\title{
ORIGINAL ARTICLE \\ Analysis of the causes and types of traumatic spinal cord injury based on 561 cases in China from 2001 to 2010
}

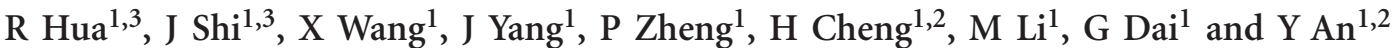

Objectives: A remarkable increase in traumatic spinal cord injury (TSCI) morbidity has occurred in China from 2001 to 2010 due to rapid industrial and economic development; this increase seriously threatens public health. The current study investigated the major causes and severity of TSCl in 561 hospitalized TSCl patients who came from all over China to the General Hospital of Chinese People's Armed Police Forces.

Methods: Information (including each patient's age, gender, time and cause of injury and severity of spinal cord injury (SCl, complete or incomplete)) regarding 561 hospitalized TSCI patients whose injuries occurred between 2001 and 2010 was retrospectively analyzed.

Results: Among the 561 patients, the youngest was 9 months old and the oldest was 67 years old; the average patient age was $34.74 \pm 12.24$ years. The sex ratio was 4.1:1 (male:female). The injuries were primarily caused by transportation accidents $(51.2 \%)$, falling from a height $(23.9 \%)$, tamping $(8.6 \%)$, stumbling $(8.0 \%)$, stabbing $(3.0 \%)$ and crushing $(1.8 \%)$. Although no statistically significant associations were observed between the different injury causes and severity of the injury, a statistically significant association was observed between the different injury causes and levels of the lesion.

Conclusion: Transportation accidents, falling from a height, tamping, stumbling, stabbing and crushing are the most common causes of TSCl. No statistically significant relationships were observed between certain injury causes and either complete or incomplete injury. However, different injury causes usually led to different levels of the lesion. No statistical differences were observed between the levels of the lesion and either complete or incomplete injury.

Spinal Cord (2013) 51, 218-221; doi:10.1038/sc.2012.133; published online 27 November 2012

Keywords: spinal cord trauma; etiology; statistical data analyses; incidence; epidemiology

\section{INTRODUCTION}

Traumatic spinal cord injury (TSCI) refers to any injury to the spinal cord that is caused by direct or indirect trauma. TSCI patients may suffer from conditions such as spasticity, sensory changes, sphincter dyssynergia and exaggereted reflex activities. The symptoms and signs vary depending on the levels of the lesion. TSCIs seriously threaten public health and longevity. The survival rate of TSCI patients is 30\% lower than that of the total population during the same period. ${ }^{1,2}$ Because of the rapid development of industries and the industrial economy in China, the incidence of TSCIs has rapidly increased. However, due to lack of large samples and multi-center investigations, it is difficult to obtain accurate epidemiological data regarding the details of TSCIs across the country. Studies have demonstrated that TSCI incidence per million population per year is 73.0 in Taiwan (2000-2003), 15.0 in Australia (2007-2008), 44.0 in Russia (19941996), 13.8 in Finland (1976-2005) and 40.0 in USA (2005). ${ }^{3-7}$ It is estimated that the annual incidence in Beijing is 60.6 per million, ${ }^{8}$ which is much higher than the reported figures for some other countries and regions. A 10-fold increase has occurred in Beijing compared with the rates from the 1980s (6.8 per million) to 2002 (60 per million).

A constant increase in the incidence of TSCIs was observed in many studies conducted within and outside of China. Transportation injuries were the leading injury cause of TSCIs in many developed countries, such as the USA, Canada, Australia, New Zealand and some West European countries. ${ }^{9-13}$ However, falling was the primary injury cause of TSCI in developing countries, such as Russia, Pakistan, Nepal and some portions of southern Asia. ${ }^{14-16}$

Similar to other developing countries, the top three causes of TSCI in the hospitalized patients in Beijing (according to a sampling survey conducted in 2002) were falling from a height (37.5\%), transportation accidents $(26.9 \%)$ and being struck by an object $(16.3 \%){ }^{8}$ In the present study, 561 TSCI patients whose injuries occurred between 2001 and 2010 were recruited. These patients came from all over China. This study primarily focused on the following questions: (1) What are the top causes of TSCI in update China? (2) Is there any correlation between the causes of TSCI and the severity of the injury (complete or incomplete injury)? and (3) Is there any correlation

${ }^{1}$ Department of Stem Cell Transplantation, The General Hospital of Chinese People's Armed Police Forces, Beijing, China and ${ }^{2}$ Beijing Neurosurgical Institute, Beijing Tiantan Hospital, Capital Medical University, Beijing, China

${ }^{3}$ These authors contributed equally to this work.

Correspondence: Dr Y An, Department of Stem Cell Transplantation, The General Hospital of Chinese People's Armed Police Forces, No. 69, Yongding Road, Haidian District, Beijing 100039, China.

E-mail: doctoran2010@hotmail.com

Received 19 June 2012; revised 28 August 2012; accepted 9 October 2012; published online 27 November 2012 
between the causes of TSCI and the levels of the lesion? We used these questions to examine epidemiological data regarding TSCIs between 2001 and 2010.

\section{MATERIALS AND METHODS}

\section{Patients}

All 561 TSCI patients whose injuries occurred between 2001 and 2010 received routine emergency treatment in their local hospitals after onset. They were then transferred to our hospital (one of the most qualified Chinese hospitals for TSCI repair and rehabilitation that is open to the entire population) for further care and rehabilitation. A retrospective analysis was performed following the hospitalization. All of the cases were confirmed as TSCIs based on the clear history of traumatic injury, magnetic resonance imaging and physical examination. Information was collected from each patient, including the patient's age, gender, injury time and injury causes.

\section{Standards}

1. Classifications of TSCI injury causes: According to version 1.2 of the International Classification of External Causes of Injuries, the causes of the patients' injuries were categorized as follows: (1) transportation accidentany incident involving a transportation device, including traffic injuries; (2) falling from a height- of at least $1 \mathrm{~m}$ above the ground; (3) tampinghit or struck by a moving object; (4) stumbling-slipping or falling on the same level; (5) stabbing-being stabbed with a knife, sword or other sharp implement; (6) crushing — being squeezed horizontally between heavy objects.

2. Classifications of the severity of the injury: One method is to classify a SCI as either a complete injury or an incomplete injury. 'Complete injury' refers to complete spinal cord transaction, which results in total denervation below the level of the lesion. 'Incomplete injury' refers to a partial transaction of the spinal cord, which results in incomplete denervation below the level of the lesion. ${ }^{17}$ Another method is to classify the SCI defined by the skeletal level according to the anatomical identity of the level of the lesion. The spinal cord is anatomically divided into the cervical, thoracic and lumbar cords according to the location in the bony spinal column. Therefore, injuries can be classified as cervical, thoracic or lumbar cord injuries. With the exception of patients with a single level of the lesion, patients may also have TSCIs with combined cervical and thoracic cord injuries or combined thoracic and lumbar cord injuries.

\section{Data}

Original medical records were typed into a SQL database. The derived data were statistically analyzed using the SPSS 16.0 software program. The measurements include the means, maxima, minima and standard deviations. Comparisons of the frequency of injury within the group were performed with the chi-square test and $P<0.05$ was used as the cutoff for statistical significance.

\section{RESULTS}

The TSCI patients in this study ranged from 9 months old to 67 years old; the average patient age at baseline was $34.74 \pm 12.24$ years; the average patient age at injury was $31.85 \pm 12.15$ years; there were 451 men $(80.4 \%)$ and 110 women $(19.6 \%)$, which resulted in a sex ratio of 4.1:1, respectively (Table 1 ). There were 280 complete injury cases $(49.9 \%)$ and 281 incomplete injury cases (50.1\%). The six most common causes of injury, which were the focus in further analyses, were transportation accidents (51.2\%), falling from a height $(23.9 \%)$, tamping $(8.6 \%)$, stumbling $(8.0 \%)$, stabbing $(3.0 \%)$ and crushing $(1.8 \%)$. The total number of patients with these six main injury causes was 541.It also showed that the mean ( \pm s.d.) age of stumbling was $40.67 \pm 12.73$ years, which was older than the high falls group $(P=0.003,95 \%$ confidence interval, 2.17-10.28) (Table 1).
Table 1 Cause of $\mathrm{TSCl}$ among the 561 patients

\begin{tabular}{lrccc}
\hline $\begin{array}{l}\text { Cause } \\
\text { Cases }\end{array}$ & $\begin{array}{c}\text { Percentage } \\
\text { (\%) }\end{array}$ & $\begin{array}{c}\text { Age at baseline } \\
\text { (Years) }\end{array}$ & $\begin{array}{c}\text { Age at injury } \\
\text { (Years) }\end{array}$ \\
\hline $\begin{array}{l}\text { Transportation } \\
\text { accident }\end{array}$ & 287 & 51.2 & $34.41 \pm 12.72$ & $31.73 \pm 12.34$ \\
Falling from a & 134 & 23.9 & $34.44 \pm 11.32$ & $31.84 \pm 11.51$ \\
height & & & & \\
Tamping & 48 & 8.6 & $34.15 \pm 8.84$ & $31.51 \pm 9.46$ \\
$\begin{array}{l}\text { Stumbling } \\
\text { Stabbing }\end{array}$ & 45 & 8.0 & $40.67 \pm 12.73$ & $37.74 \pm 13.22$ \\
Crushing & 17 & 3.0 & $28.35 \pm 14.66$ & $23.78 \pm 11.69$ \\
Gunshot wound & 10 & 1.8 & $28.10 \pm 7.52$ & $26.30 \pm 7.02$ \\
Diving & 6 & 1.1 & $29.33 \pm 6.38$ & $24.33 \pm 5.57$ \\
Spinal surgery & 6 & 1.1 & $36.67 \pm 11.33$ & $21.67 \pm 13.31$ \\
Blunt-force trauma & 2 & 0.4 & $50,52^{\mathrm{a}}$ & $47.50 \pm 2.12$ \\
Traction by machine & 2 & 0.4 & $21,36^{\mathrm{a}}$ & $19,26^{\mathrm{a}}$ \\
Total & 561 & 100 & $34.74 \pm 12.24$ & $31.85 \pm 12.15$ \\
\hline
\end{tabular}

Abbreviation: TSCI, traumatic spinal cord injury.

aThe actual age of the two patients.

Table 2 Comparison of primary causes among $\mathrm{TSCl}$ patients according to gender

\begin{tabular}{|c|c|c|}
\hline \multirow[t]{2}{*}{ Primary cause } & \multicolumn{2}{|c|}{ Gender } \\
\hline & Male & Female \\
\hline Transportation accident & $215(49.8 \%)$ & $72(66.1 \%)$ \\
\hline Falling from a height & $114(26.4 \%)$ & $20(18.3 \%)$ \\
\hline Tamping & $46(10.6 \%)$ & $2(1.8 \%)$ \\
\hline Stumbling & $33(7.6 \%)$ & $12(11.0 \%)$ \\
\hline Stabbing & $14(3.2 \%)$ & $3(2.8 \%)$ \\
\hline Crushing & $10(2.3 \%)$ & 0 \\
\hline Total & 432 (100.0\%) & 109 (100.0\%) \\
\hline$P$ value & \multicolumn{2}{|c|}{0.003} \\
\hline
\end{tabular}

Abbreviation: TSCl, traumatic spinal cord injury.

Statistically significant differences in the causes of SCI were observed between genders $(P=0.003)$. For both male and female patients, the most common cause of injury was transportation accident $(49.8 \%$ of male patients and $66.1 \%$ of female patients), and the second most common injury cause was falling from a height $(26.4 \%$ of male patients and $18.3 \%$ of female patients) (Table 2 ).

The injury causes did not correlate with whether the resulting injuries were complete or incomplete among the 561 TSCI patients $(P=0.251)$. The ratios of incomplete injuries to complete injuries due to different injury causes were 137:150, 64:70, 25:23, 25:20, 13:4 and 4:6 for transportation accidents, falling from a high place, tamping, stumbling, stabbing and crushing, respectively (Table 3 ).

A statistically significant correlation was observed between the levels of the lesion and the different injury causes among the 561 TSCI patients $(P<0.001)$. Different injury causes usually led to injuries in specific levels of the lesion. For example, among the 561 patients included in this study, $55.7 \%$ of the transportation accidents resulted in cervical cord injuries, $45.5 \%$ of the falls from a height resulted in cervical cord injuries, $39.6 \%$ of the tampings resulted in thoracic cord injuries, $55.6 \%$ of the stumblings resulted in cervical cord injuries, $64.7 \%$ of the stabbings resulted in thoracic cord injuries and $60.0 \%$ of the crushings resulted in thoracic cord injuries (Table 4). 
No statistically significant correlation was observed between the levels of the lesion and the severity of the injury (complete or incomplete) among the 561 TSCI patients $(P=0.048)$. Cervical cord injury was the most common injury in both incomplete $(48.3 \%)$ and complete (47.9\%) TSCIs (Table 5).

\section{DISCUSSION}

Previous studies have shown that male SCI patients outnumber female SCI patients. ${ }^{6-8}$ In Beijing, the 2002 sampling survey shows that the ratio of males to females was 3.11:1.ref.3 In the current study, the gender ratio is $4.1: 1$, which also indicates that males account for the majority of TSCIs. In both male and female patients, transportation accidents are the primary injury cause of TSCIs, accounting for $49.8 \%$ and $66.1 \%$ of all TSCIs, respectively. The six most common TSCI injury causes in this study are transportation accidents, falling from a height, tamping, stumbling, stabbing and crushing, which is consistent with the results of relevant studies that were conducted during the last two decades in some developed countries (USA, 2008; Canada, 1997-2001; Australia, 2006-07) and China (Beijing, 2007) ${ }^{9-11,18}$ The epidemiological analysis of TSCI patients in Beijing in 2007 demonstrated that transportation accidents caused $44.3 \%$ of TSCIs $^{18}$ (significantly higher than the $22.3 \%{ }^{4}$ reported in 2002), becoming the primary injury cause of all TSCIs. In the current study, $51.2 \%$ of TSCIs were caused by transportation accidents; this result is higher than the figure obtained from Beijing in $2007 .{ }^{18}$ Compared with previous studies, the current study reveals the following characteristics: (1) The average age of the patients in the study is $34.74 \pm 12.24$ years, which is similar to the average age of TSCI patients in other developing countries. The mean age is lower in Iran (31 years), Russia (34.2 years) and Jordan (33 years). ${ }^{5,14,19}$ The younger average age of TSCI patients in developing countries is

Table 3 Comparison of the severity of the injury

\begin{tabular}{|c|c|c|}
\hline \multirow[t]{2}{*}{ Cause } & \multicolumn{2}{|c|}{ The severity of $\mathrm{TSCl}$} \\
\hline & Incomplete & Complete \\
\hline Transportation accident & $137(51.1 \%)$ & $150(54.9 \%)$ \\
\hline Falling from a height & $64(23.9 \%)$ & $70(25.6 \%)$ \\
\hline Tamping & $25(9.3 \%)$ & $23(8.4 \%)$ \\
\hline Stumbling & $25(9.3 \%)$ & $20(7.3 \%)$ \\
\hline Stabbing & $13(4.9 \%)$ & $4(1.5 \%)$ \\
\hline Crushing & $4(1.5 \%)$ & $6(2.2 \%)$ \\
\hline$P$ value & \multicolumn{2}{|c|}{0.251} \\
\hline
\end{tabular}

Abbreviation: TSCl, traumatic spinal cord injury. related to the large number of young people working in the industrial economy and inherent habits and lifestyles. For example, young people usually sleep on rooftops during hot summers in Turkey, and young people climb trees to pick fruit in South Asia. Activities such as these are more likely to cause TSCIs. (2) Transportation accidents have become the primary injury cause of TSCIs. In 2002, the primary cause of TSCIs in Beijing was falling from a high place, which was related to the accelerated industrialization process and the flourishing construction industry during that period. However, 5 years later, transportation accidents had replaced falling from a height as the primary cause of TSCIs in Beijing. The number of private cars in Beijing was less than 1.2 million in 2002, nearly 2.4 million in 2007 and nearly 4.8 million in 2010, representing an approximately fourfold increase over 8 years. The percentage of TSCIs caused by transportation accidents was $49.8 \%$, which was twice as high as in 2002; this increase is also consistent with the increased number of vehicles. This phenomenon has spread all over China, which suggests that the Chinese government must further strengthen transportation safety. Both medical and insurance institutions should modify their strategies to address this trend.

Transportation accidents, falling from a height and stumbling primarily cause cervical cord injuries (approximately 50\% of each injury cause leads to SCIs). Tamping, stabbing and crushing primarily cause thoracic cord injuries, accounting for 39.6\%, 64.7\% and $60.0 \%$ of the TSCIs, respectively. This specific cause-level relationship can be explained by the anatomical characteristics of the spinal column; cervical vertebrae are small but highly mobile, which allows them to be easily dislocated, causing cervical cord injury. ${ }^{20}$ The ribs and thoracic vertebrae form the thoracic cavity, which limits the movement of the thoracic vertebrae and stabilizes them. Therefore, only a violent external force or from the insertion of a foreign object into the narrow space between two vertebrae can damage the thoracic cord.

Table 5 Analysis of the severity of the injury and the levels of the lesion

\begin{tabular}{|c|c|c|c|c|c|}
\hline \multirow{2}{*}{$\begin{array}{l}\text { The severity } \\
\text { of the injury }\end{array}$} & \multicolumn{5}{|c|}{ The levels of the lesion } \\
\hline & $\begin{array}{c}\text { Cervical } \\
\text { cord }\end{array}$ & $\begin{array}{c}\text { Cervico-thor- } \\
\text { acic combined } \\
\text { cord }\end{array}$ & $\begin{array}{c}\text { Thoracic } \\
\text { cord }\end{array}$ & $\begin{array}{l}\text { Thoracico- } \\
\text { lumbar com- } \\
\text { bined cord }\end{array}$ & $\begin{array}{l}\text { Lumbo- } \\
\text { sacral cord }\end{array}$ \\
\hline $\begin{array}{l}\text { Incomplete } \\
\text { Complete } \\
P \text { value }\end{array}$ & $\begin{array}{l}129(48.1 \%) \\
136(49.8 \%)\end{array}$ & $\begin{array}{r}10(3.7 \%) \\
9(3.3 \%)\end{array}$ & $\begin{array}{c}84(31.3 \%) \\
102(37.4 \%) \\
0.048\end{array}$ & $\begin{array}{l}22(8.2 \%) \\
18(6.6 \%)\end{array}$ & $\begin{array}{r}23(8.6 \%) \\
8(2.9 \%)\end{array}$ \\
\hline
\end{tabular}

Table 4 Analysis of primary injury causes and the levels of the lesion of the $561 \mathrm{TSCl}$ patients

\begin{tabular}{|c|c|c|c|c|c|}
\hline \multirow[t]{2}{*}{ Cause } & \multicolumn{5}{|c|}{ The levels of the lesion } \\
\hline & Cervical cord & Cervico-thoracic combined cord & Thoracic cord & Thoracico-lumbar combined cord & Lumbo-sacral cord \\
\hline Transportation accident & $160(55.7 \%)$ & $13(4.5 \%)$ & $94(32.8 \%)$ & $13(4.5 \%)$ & $7(2.4 \%)$ \\
\hline Falling from a height & $61(45.5 \%)$ & $3(2.2 \%)$ & $45(33.6 \%)$ & $11(8.2 \%)$ & $14(10.4 \%)$ \\
\hline Tamping & $14(29.2 \%)$ & 0 & $19(39.6 \%)$ & $11(22.9 \%)$ & $4(8.3 \%)$ \\
\hline Stumbling & $25(55.6 \%)$ & $2(4.4 \%)$ & $11(24.4 \%)$ & $2(4.4 \%)$ & $5(11.1 \%)$ \\
\hline Stabbing & $4(23.5 \%)$ & 0 & $11(64.7 \%)$ & $2(11.8 \%)$ & 0 \\
\hline Crushing & $1(10.0 \%)$ & $1(10.0 \%)$ & $6(60.0 \%)$ & $1(10.0 \%)$ & $1(10.0 \%)$ \\
\hline$P$ value & & & $<0.001$ & & \\
\hline
\end{tabular}

Abbreviation: TSCI, traumatic spinal cord injury. 
No relationship was observed between the injury causes and the severity of TSCI (complete or incomplete). The ratio of incomplete to complete injuries due to transportation accidents, falling from a height, tamping, stumbling, stabbing and crushing were 137:150, $64: 70,25: 23,25: 20,13: 4$ and 4:6, respectively; these ratios were not significantly different. As mentioned above, the ability of a TSCI event to lead to complete or incomplete TSCI is apparently related to the severity of the external forces and the anatomical structure of the levels of the lesion. Injuries to more vulnerable spinal spots and injuries caused by more powerful external forces were more likely to cause complete TSCIs.

This retrospective analysis of 561 hospitalized TSCI cases injured between 2001 and 2010 in China reveals two primary conclusions. First, with economic development, the incidence and etiology of TSCI in China is changing from that of developing countries to that of developed countries, which mirrors China's changing economic position in the world. For example, transportation accidents $(51.2 \%)$ have eclipsed falling from a height to become the leading injury cause of TSCIs in China; this phenomenon differs from other developing countries or regions. Transportation accidents have become the primary cause of TSCIs in China owing to the rapid increase in the number of motor vehicles. A lifestyle involving more non-manual labor and private cars, similar to that in developed countries, has contributed to this change. The average age of the patients in our study was younger than the data reported for developed countries. Because developed countries typically contain higher proportions of older individuals, TSCI patients are typically older in developed countries. Second, although different injuries usually led to injuries in specific levels, the injury cause is not statistically correlated with the severity of TSCI (complete or incomplete). A relationship exists between complete or incomplete TSCI and the severity of the external forces and the anatomical structure of the spinal cord.

Although this study has some limitations, such as the small sample size, lack of the information on seat belt or helmet use and the single source of patients, it is a valuable supplement to TSCI epidemiology and provides updated data on TSCIs in China. The study also demonstrates how the modernization of China has affected the incidence and nature of TSCIs, which is useful for the Chinese government, hospitals and medical insurance companies.

\section{DATA ARCHIVING}

There were no data to deposit.

\section{CONFLICT OF INTEREST}

The authors declare no conflict of interest.

1 Ahoniemi E, Pohjolainen T, Kautiainen H. Survival after spinal cord injury in Finland. J Rehabil Med 2011; 43: 481-485.

2 Cripps RA, Lee BB, Wing P, Weerts E, Mackay J, Brown D. A global map for traumatic spinal cord injury epidemiology: towards a living data repository for injury prevention. Spinal Cord 2011; 49: 493-501.

3 Yang $\mathrm{N}-\mathrm{P}$, Deng $\mathrm{C}-\mathrm{Y}$, Lee $\mathrm{Y}-\mathrm{H}$, Lin $\mathrm{C}-\mathrm{H}$, Kao $\mathrm{C}-\mathrm{H}$, Chou P. The incidence and characterization of hospitalized acute spinal trauma in Taiwan-a population-based study. Injury Int J Care injured 2008; 39: 443-450.

4 Norton L. Spinal cord injury, Australia 2007-08: Injury research and statistics series no. 52. Cat. no. INJCAT 128. AlHW: Canberra, 2010.

5 Kondakov EN, Simonova IA, Poliakov IP. The epidemiology of injuries to the spine and spinal cord in Saint Petersburg. Zhurnal Voprosy Neirokhirurgii Imeni $\mathrm{N}-\mathrm{N}-$ Burdenko 2002; 2: 50-53.

6 Ahoniemi E, Alaranta H, Hokkinen E-M, Valtonen K, Kautiainen H. Incidence of traumatic spinal cord injuries in Finland over a 30-year period. Spinal Cord 2008; 46: 781-784.

7 Farry A, Baxter D. The Incidence and Prevalence of Spinal Cord Injury in Canada: Overview and Estimates Based on Current Evidence. Rick Hansen Institute and Urban Futures Institute: Canada, 2010.

8 Li J, Liu G, Zheng Y, Hao C, Zhang Y, Wei B et al. The epidemiological survey of acute traumatic spinal cord injury (ATSCI) of 2002 in Beijing municipality. Spinal Cord 2011; 49: 777-782.

9 National Spinal Cord Injury Statistical Center. Spinal cord injury. Facts and figures at a glance. J Spinal Cord Med 2005; 28: 379-380.

10 Pickett GE, Campos-Benitez M, Keller JL, Duggal N. Epidemiology of traumatic spinal cord injury in Canada. Spine 2006; 31: 799-805.

11 Cripps R. Spinal Cord Injury, Australia, 2006-07 Injury Research and Statistics Series Number 48 . Cat. no. INJCAT 119. AlHW: Adelaide, 2008

12 Dixon GS, Danesh JN, Caradoc-Davies TH. Epidemiology of spinal cord injury in New Zealand. Neuroepidemiology 1993; 12: 88-95.

13 Divanoglou A, Levi R. Incidence of traumatic spinal cord injury in Thessaloniki, Greece and Stockholm, Sweden: a prospective population-based study. Spinal Cord 2009; 47: $1-6$.

14 Silberstein B, Rabinovich S. Epidemiology of spinal cord injuries in Novosibirsk, Russia.. Paraplegia 1995; 33: 322-325.

15 Raja IA, Viohra AH, Ahmed M. Neurotrauma in Pakistan. World J Surgery 2001; 25: 1230-1237.

16 Bajracharya S, Singh M, Singh GK, Shrestha BP. Clinico-epidemiological study of spinal injuries in a predominantly rural population of eastern Nepal: a 10 years' analysis. Indian J Orthop 2007; 41: 286-289.

17 American Spinal Injury Association and International Spinal Cord Society. International Standards for Neurological Classification of Spinal Cord Injury. American Spinal Injury Association and International Spinal Cord Society: Chicago, IL, 2006.

18 Hao C, Li J, Zhou H, Kang H, Li S, Liu G et al. Epidemiology characteristics of Spinal Cord Injury in hospital: 1264 cases report. Chinese J Rehabilitation Theory Practice 2007; 13: 1011-1013. in Chinese.

19 Yousefzadeh CS, Safaee M, Alizadeh A, Ahmadi DM, Taghinnejadi O, Koochakinejad L. Epidemiology of traumatic spinal injury: a descriptive study. Acta Med Iran 2010; 48: 308-311.

20 Zhang Q, Jia L. Statistical analysis of clinical data in patients with spinal cord injury. Acad J Second Military Med Univ 2003; 24: 684-686. in Chinese. 